\title{
Tips on Halterbreaking Cattle ${ }^{1}$
}

\section{Chris DeCubellis²}

Raising an animal has traditionally been one of the most popular and rewarding $4-\mathrm{H}$ projects. Raising a steer or heifer can teach a young person valuable life skills including time management, decision-making, and problem-solving. Young people can also learn how to properly care for a livestock animal as they learn the science of animal husbandry. When working with an animal as large as a steer or heifer, some risks are involved. These risks can be greatly reduced if project animals are properly halterbroken and trained before any fairs or exhibitions.

Here are some tips on halterbreaking cattle:

- The younger the calf at the time of halterbreaking, the easier it is.

- A beef project is much easier when a calf is halterbroken before the initial weigh-in.

- Ideally your animal will already be weaned before the first weigh-in.

- Both weaning and transporting to the weigh-in can be stressful to the animals. Breaking these up into two separate events will lower the overall stress to the calf.

- Your equipment, your facilities, your demeanor, and the demeanor of your animal will all play a role in how difficult or easy the halterbreaking process will be for your animal.

- It is important to have a solid and secure pen/paddock in which to initially halterbreak your animal.
- It is best if the youth (with parental oversight/supervision) is the one who feeds/cares for the animal daily. This will allow the animal to become comfortable with the youth's presence.

- A good training halter and lead is necessary to control your animal.

- Always make sure the halter is properly positioned high up on the bridge of the nose so that it won't cut off airflow if the animal balks/resists leading. Check the fit of the halter daily-these animals can grow fast, and you do not want a halter squeezing the animal too tightly.

- Often, teaching cattle to be tied to a solid post, tree, or something solid will go a long way to teaching an animal to lead. The animal learns it can't escape/break the rope.

- Make sure that you do not position yourself between the animal and a fence until the animal has learned to be calm and no longer afraid of you.

- Never tie an animal to something that is rickety, loose, or easy to break.

- Tie animals high (about 3-4 feet off the ground) with about 12-18 inches of slack between the halter and whatever they are tied to.

- Always tie the animal with a quick-release slipknot, like a "manger knot." See Figure 1 below for an example of a quick-release knot.

- Once the animal is used to being tied and stands quietly while tied, you can start handling/petting/touching the animal to get it used to being touched.

1. This article is $4 \mathrm{H} 421$, one of a series of the Florida 4-H Youth Development Program, UF/IFAS Extension. Original publication date November 2021. Visit the EDIS website at https://edis.ifas.ufl.edu/ for the currently supported version of this publication.

2. Chris DeCubellis, dairy/animal sciences 4-H state specialized agent, UF/IFAS 4-H Youth Development Program; UF/IFAS Extension, Gainesville, FL 32611.

The Institute of Food and Agricultural Sciences (IFAS) is an Equal Opportunity Institution authorized to provide research, educational information and other services

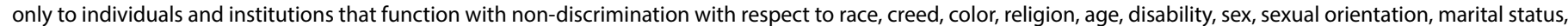

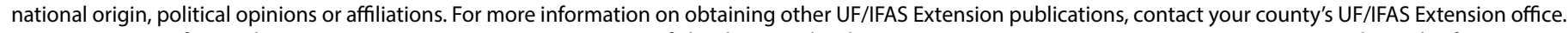
U.S. Department of Agriculture, UF/IFAS Extension Service, University of Florida, IFAS, Florida A \& M University Cooperative Extension Program, and Boards of County Commissioners Cooperating. Nick T. Place, dean for UF/IFAS Extension. 
- Begin handling on the tail head and along the back. Don't begin rubbing the head, because this can encourage your animal to butt you with its head.

- Some cattle love to kick, so proceed with care when handling.

- When an animal is comfortable being handled and respects being tied, you can begin leading. Young people should be supervised at all times, but especially during leading. Leading an animal to and from water is often a good way to begin leading an animal.

- It's good to find a treat that your animal really likes, like alfalfa cubes or pieces of apple. Give this treat to your animal only when you are handling or leading it. The calf will learn to associate this treat with you working with it.

- After an animal is used to being handled, you can often calm a beef animal down by rubbing or brushing it.

- After the animal is used to being handled and is leading fairly well, you can begin introducing a show stick to help train the animal how to properly "set up." You can also use the show stick to rub the animal to provide a soothing, calming effect.

- Practice early and often with the show stick at home! Always keep the tip pointed down while leading. The show stick is a tool to calm your animal and help it set up its feet and legs and straighten its back. It is not a tool to hit your animal.

- The more you groom your animal during your project, the easier grooming will be at the show.

- Leading your animal every day after breaking it will increase its muscle definition and make it behave better at the fair/show.

- Families are encouraged to watch this excellent video on halterbreaking a heifer from the UF/IFAS Range Cattle Research and Education Center's Virtual Youth Field Day in 2020: https://www.youtube.com/ watch?v=AQYP6vlYbWA.

There are many ways to halterbreak a steer or heifer; keep in mind that these are just some tips to help you succeed. If a youth exhibitor takes time to properly train their project animal, they will lay the foundation to have a successful experience at a fair or exhibition. Safety is always the most important aspect of working with large animals, and youth should always have knowledgeable adult supervision while working with their animals. Youth can constantly build on their knowledge of working with animals by learning all they can from other exhibitors, experienced adults, county Extension agents and FFA advisors, parents, and their own past experiences.
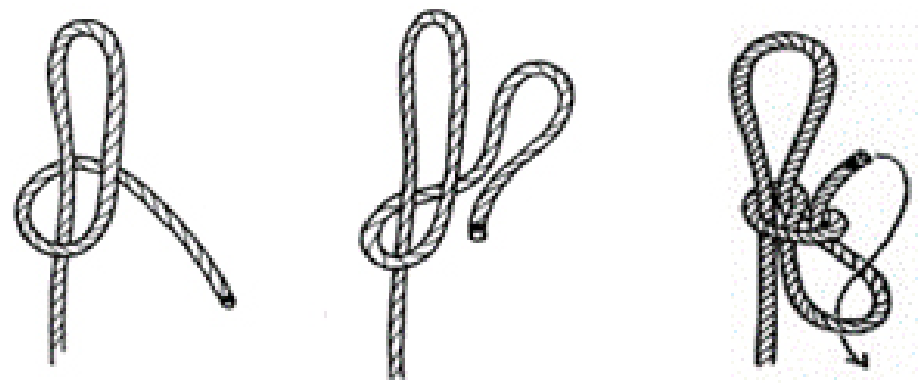

Figure 1. An example of a slipknot.

Credits: Courtesy of the Florida State Fair 2022 Beef Skillathon Manual (2021)

\section{References}

DeCubellis, C.D.(2021, in press). Florida state fair 2022 beef skillathon manual.

Ward, C. K. (1996). Life skill development related to participation in 4-H animal science projects. Journal of Extension, 34(2), 2RIB2. Retrieved October 13, 2021, from https://archives.joe.org/joe/1996april/rb2.php

Warren, M. (2020, July 16). Halter breaking live class session - video and $Q$ \& $A$. YouTube. https://www.youtube.com/ watch?v=AQYP6vlYbWA. 